\title{
A acessibilidade nos sites do Poder Executivo estadual à luz dos direitos fundamentais das pessoas com deficiência
}

\author{
Rosane Leal da Silva \\ Universidade Federal de Santa Maria (UFSM) \\ Letícia Almeida de la Rue \\ Universidade Federal de Santa Maria (UFSM)
}

\begin{abstract}
Este artigo investiga se a acessibilidade, analisada à luz dos direitos das pessoas com deficiência, é valorizada no desenvolvimento do governo eletrônico e se reflete na estrutura dos portais governamentais, contribuindo para a concretização do direito de participação política deste grupo social. Para tanto, com apoio do método dedutivo e da técnica de observação direta, sistemática e não participante, verificou-se a acessibilidade nos portais do Poder Executivo estadual de oito unidades da federação, contrastando-se a realidade destes sites com as determinações de cartilhas governamentais que preveem padrões mínimos sobre o tema. Concluiu-se que a acessibilidade nos sites pesquisados é mínima, dificultando assim o exercício de uma cidadania mais ativa por parte das pessoas com deficiência, uma vez que o acesso é a primeira condição de possibilidade para a participação.
\end{abstract}

Palavras-chave: governo eletrônico; internet; direitos fundamentais; pessoas com deficiência; acessibilidade.

La accesibilidad en sitios del Poder Ejecutivo estadual desde la perspectiva de los derechos fundamentales de las personas con discapacidad

Este trabajo investiga se la accesibilidad, desde la perspectiva de las personas con discapacidad, es valorada en el desarrollo del gobierno electrónico y se refleja en la estructura de los portales gubernamentales, contribuyendo para la realización del derecho a la participación política de este grupo social. Para esto, con apoyo del método deductivo y dela técnica de la observación directa, sistemática y no participante, se analizó la accesibilidad en los portales del Poder Ejecutivo de ocho entidades federativas, contrastando la realidad de estos sitios con lo dispuesto en los folletos gubernamentales que contienen estándares mínimos de accesibilidad. Se concluyó que la accesibilidad en los sitios investigados es mínima, lo que dificulta el ejercicio de una ciudadanía más activa por parte de las personas con discapacidad, una vez que el acceso es la primera condición de posibilidad para la participación.

Palabras clave: gobierno electrónico; internet; derechos fundamentales; personas con discapacidades; accesibilidad.

DOI: http://dx.doi.org/10.1590/0034-7612130130

(cc) BY-NC

Artigo recebido em 4 fev. 2014 e aceito em 22 set. 2014. 
Accessibility in the State Executive Power units through the perspective of fundamental rights of people with disabilities

This article investigates if accessibility, from the perspective of people with disabilities, is valued in the development of electronic government, and if it is reflected in the structure of government portals, contributing to concretize the right to political participation of this social group. For that, with support of deductive method and technique of direct, systematic and non-participant observation, the accessibility in the portals of eight State Executive Power units was verified, contrasting the reality of these sites with the provisions of governmental booklets that contain minimum standards on the subject. It was concluded that, in the studied sites, accessibility is minimal, hindering the pursuit of a more active citizenship for people with disabilities, since access is the first condition of possibility for participation.

KEYWORDs: electronic government; internet; fundamental rights; people with disabilities; accessibility.

\section{Introdução}

Com o desenvolvimento tecnológico das últimas décadas, passou-se a discutir acerca das perspectivas de fortalecimento da cidadania propiciadas pelo uso das tecnologias da informação e comunicação (TICs). Avançam as políticas de governo eletrônico, com destaque para a crescente utilização de portais do poder público, que se vale de páginas na internet para divulgar tanto serviços quanto informações sobre sua atuação, seus projetos e programas.

Argumenta-se que, a partir desses portais, os indivíduos podem não apenas acessar de maneira mais transparente as informações públicas, mas também exercer de modo mais efetivo o controle social. Contudo, para que essa nova expressão de cidadania, mais ativa e participativa, se concretize, não basta a simples existência de sites governamentais, na medida em que tão essencial quanto é garantir a acessibilidade, ou seja, o acesso a portais do poder público independentemente do tipo de usuário, situação ou ferramenta.

Apesar de acessibilidade possuir um conceito amplo, referindo-se à necessidade de garantir o acesso independente da condição pessoal de cada um, existe um grupo que merece especial destaque: as pessoas com deficiência. Dentre as dificuldades inerentes à sua condição pessoal, que não raro levam à negação de direitos e à exclusão social, somam-se os entraves com a utilização de tecnologias, que muitas vezes requerem a utilização de softwares específicos para o acesso ao conteúdo digital. Assim, se por um lado as TICs podem contribuir para a democracia, no caso das pessoas com deficiência essa participação cidadã apenas será efetivada caso as premissas básicas de acessibilidade digital sejam consideradas na implantação do governo eletrônico.

Partindo de tais premissas, neste artigo a acessibilidade será abordada à luz dos direitos das pessoas com deficiência, questionando-se: o conceito de acessibilidade é valorizado no desenvolvimento do governo eletrônico e se reflete na estrutura dos portais governamentais contribuindo, assim, para a concretização dos direitos fundamentais das pessoas com deficiência, em especial o direito de participação política? A partir daí, o presente artigo tem por objetivo 
verificar qual o tratamento concedido à acessibilidade nos portais do Poder Executivo estadual, contrastando-se a realidade observada nesses sites com as determinações previstas em cartilhas governamentais que preveem a observância de padrões mínimos de acessibilidade, de modo a verificar se os portais em questão contribuem de maneira adequada para garantir os direitos fundamentais de participação política das pessoas com deficiência.

Para tanto, optou-se pelo método de abordagem dedutivo, em conjunto com a técnica de pesquisa bibliográfica, por meio da análise doutrinária sobre o tema. Como método de procedimento, utilizou-se o comparado, com o auxílio da técnica de observação direta, sistemática e não participante nos sites de oito unidades da federação (São Paulo, Rio de Janeiro, Minas Gerais, Rio Grande do Sul, Paraná, Bahia, Distrito Federal e Santa Catarina), realizada durante mês de novembro de 2013. Adotou-se, como critério para seleção, a participação de cada um no Produto Interno Bruto (PIB) brasileiro, conforme estatísticas do Instituto Brasileiro de Geografia e Estatística (IBGE), na pesquisa "Contas Regionais do Brasil", que abrange o período de 2005 a 2009.

\section{Cidadania, democracia e governo eletrônico: uma relação necessária}

Na sociedade cada vez mais conectada digitalmente, as relações sociais, políticas, econômicas passam por mudanças aceleradas e irreversíveis, gerando novos hábitos de comunicação e interação entre as pessoas. Consoante Perez Luño (2014:101), as novas tecnologias suscitam a impressão de que o tamanho do mundo diminuiu, e que os cidadãos e os povos se encontram dinamicamente mais próximos que em qualquer etapa histórica anterior. Assim, a era da informática e da telemática contribui para que se adquira a convicção de que o habitat cívico do presente possui dimensões planetárias.

Essas transformações atingem, em maior ou menor grau, todas as camadas da sociedade, inclusive grupos sociais que não raro são deixados à margem das constantes e exponenciais mudanças que a sociedade informacional gera na vida das pessoas. Por esse motivo, deve ser concedida especial atenção à situação das pessoas com deficiência, uma vez que se trata de uma parcela da sociedade que, ao longo das diferentes etapas históricas pelas quais a humanidade passou, não raro foi deixada à margem das transformações. Por esse motivo, justificam-se estudos que levem em consideração a inserção de tais pessoas no contexto da sociedade informacional.

Nesse contexto de avanço tecnológico, muito se tem questionado e discutido sobre o papel da tecnologia, em especial da internet, nas democracias contemporâneas. As amplas possibilidades de difusão da informação e de incremento de formas de participação da sociedade civil levaram diferentes teóricos a afirmar que uma nova expressão de cidadania, mais ativa e participativa, está emergindo na era da sociedade informacional.

Conforme Gomes (2005:218), as expressões democracia eletrônica, ciberdemocracia, democracia digital, e-democracy fazem referência às possibilidades de extensão das oportunidades democráticas instauradas pela infraestrutura tecnológica das redes de computadores. 
Em outras palavras, verifica-se que diferentes denominações foram concedidas às interações entre internet e participação política pelos estudiosos do tema.

Para Pinho (2008:3), o desenvolvimento e o avanço da internet, associados às tecnologias informacionais, ocasionam, no âmbito das democracias, dois efeitos diretos: a) no setor público, a melhoria nos processos governamentais, oferta de serviços de melhor qualidade e quantidade, possibilidade de maior transparência na prestação de informações das atividades do governo; b) na sociedade, a possibilidade de maior acesso às informações do Estado, maior grau de formação e articulação de grupos dentro da sociedade, possibilidade de maior cobrança de serviços ao setor público, bem como transparência nas ações deste.

É inegável que transformações na estrutura política dos Estados — ainda que algumas sejam extremamente sutis - com base no uso da tecnologia estão ocorrendo aos poucos. No Brasil, diversos órgãos dos três Poderes têm utilizado portais da web tanto como forma de disponibilização de serviços e publicação de informações, a exemplo da divulgação de dados sobre sua atuação, suas ações e programas, seus servidores etc., quanto como caminho para que o cidadão possa entrar em contato direto com o órgão, inclusive de forma participativa, opinando, por meio de consultas públicas, na elaboração de projetos de lei.

Governo eletrônico é o conceito cunhado para essa utilização das tecnologias da informação e comunicação (TICs) por parte da administração pública. No dizer de Rover (2006:99), pode ser entendido como a infraestrutura única de comunicação compartilhada por diferentes órgãos públicos a partir da qual as TICS são usadas de forma intensiva no intuito de melhorar a gestão pública e o atendimento ao cidadão. Tem como objetivo colocar o governo ao alcance de todos, ampliando a transparência das suas ações e incrementando a participação cidadã.

Piana (2007:105-106) põe especial ênfase na necessidade de entender o governo eletrônico não somente pelo lado da simples informatização de serviços existentes, mas também pela mudança da lógica de participação, com a abertura de novos canais de comunicação entre Estado e cidadãos. Observa-se, portanto, que os dois autores dão especial destaque à participação, enfatizando a necessidade de que o governo eletrônico se preocupe com a interação entre Estado e cidadãos.

Nesse sentido, as iniciativas de governo eletrônico comportam diferentes dimensões, dependendo do público ao qual se dirige a ação. Interessam, no presente trabalho, as iniciativas de governo eletrônico destinadas a oferecer serviços aos cidadãos, ou seja, à formulação de solicitações através da internet, como maneira de economizar tempo e dinheiro, evitar filas e melhorar a eficiência (Piana, 2007:121-122).

No mesmo sentido de Piana é a visão de Barbosa, Cunha e Pinto (2007:180-183), para quem o governo eletrônico, inicialmente advindo da influência ideológica da New Public Management, ou Nova Gestão Pública (NGP) — que propunha a gestão das organizações públicas calcada nos princípios orientadores de práticas gerenciais do setor privado - , foi aos poucos incorporando outras dimensões, como a transparência, o controle social, a participação, a preocupação com a inclusão social e digital, o exercício da cidadania e a responsividade do Estado. Essa perspectiva mais abrangente culminou no surgimento da utilização, mais 
recente, do termo "governança eletrônica". A governança eletrônica se divide nos seguintes aspectos: e-administração pública, relacionada com a melhoria dos processos governamentais e do trabalho interno no setor público com a utilização das TICs; e-serviços públicos, voltada à melhoria na prestação de serviços ao cidadão; e e-democracia, que diz respeito a uma participação cidadã mais ativa, possibilitada pelo uso das TICs no processo de tomada de decisão.

Por sua vez, na visão de Piana (2007:108), a governança eletrônica, ou e-governança, é um conceito que inclui as ações estatais que se apoiam no suporte digital para elaboração de políticas públicas, tomada de decisões, participação ativa na elaboração de políticas, gestão e avaliação dos resultados. São processos dinamizadores da elaboração de políticas públicas ao gerar maior participação, controle e cogestão. Tem-se, portanto, que a e-governança é entendida hoje como um conceito mais amplo do que o de governo eletrônico, se preocupando também com a adoção, por meio da tecnologia, de mecanismos que estimulem a participação da sociedade civil na condução da política.

Seguindo nessa lógica que entende o governo eletrônico não como simples prestação de serviços públicos por meio das tecnologias, Piana (2007:112-113) ressalta que o e-governo é uma forma de organização complexa e participativa, que tem várias dimensões e implica uma série de ações que vão desde a informatização dos serviços existentes até a participação cidadã na gestão do Estado. Contudo, se a própria lógica do Estado não fomenta de modo institucionalizado e sistematizado mecanismos de participação nos processos de tomada de decisão, não se pode esperar que com as TICs sejam criados canais de diálogo. Quer dizer, as TICs podem contribuir para melhorar a relação Estado-cidadão hoje existente — podem inclusive ampliá-la para locais onde essa relação não exista em razão da distância ou de outras questões formais —, mas não podem, por si só, criar mecanismos democráticos de participação se estes ainda não existem.

Nesse sentido, diversos autores têm questionado o tão festejado potencial democrático das TICs, argumentando que a tecnologia, por si só, não produzirá mudanças concretas nas democracias contemporâneas se seu uso não for feito de maneira consciente, que leve em consideração o contexto político, econômico e cultural de cada Estado.

Seguindo nessa lógica, defende Pinho (2008:18) que não é possível fazer repousar na tecnologia de forma isolada um caráter que ela não pode possuir, na medida em que existe uma distância enorme entre o que promete e o que efetivamente consegue realizar. E isto se deve ao fato de que a tecnologia não é neutra, mas sim apropriada social e politicamente. Desse modo, o autor considera que a realização das oportunidades proporcionadas pela tecnologia dependerá, fundamentalmente, do estágio de desenvolvimento político de cada país. No Brasil, país marcado pelo patrimonialismo, e onde o conceito de transparência somente começou a ser discutido nos últimos anos, encontra-se um Estado bastante resistente à abertura para procedimentos democráticos. Por outro lado, a sociedade também não pode ser mitificada como o locus do bem e das boas intenções, pois também é formada na mesma matriz patrimonialista. Paralelamente a tais características estruturais, soma-se a dificuldade de inserção das tecnologias da informação e comunicação, especialmente nas camadas sociais de mais baixa renda. 
Quer dizer, o resultado do uso da tecnologia dependerá, em larga medida, da apropriação que dela for feita. Por isso, é de fundamental importância que o Estado brasileiro implante o governo eletrônico sob uma ótica preocupada não apenas com a simples transposição de serviços físicos para a internet, mas que busque a efetivação da participação política de maneira sofisticada, empregando as tecnologias informacionais com o escopo de propiciar maior abertura à intervenção da sociedade civil na condução da democracia. Para tanto, cumpre pensar as políticas de governo eletrônico a partir da lógica das necessidades da sociedade - e não mais da lógica da administração pública, como comumente ocorre nesse campo.

E um exemplo da relevância de se considerar a lógica da necessidade do cidadão está na garantia de acesso universal aos serviços de governo eletrônico. Quer dizer, a participação cidadã na esfera pública somente poderá ser garantida caso as políticas de governo eletrônico se preocupem em abrir espaço para que toda e qualquer pessoa possa acessar os sites governamentais, consultar as informações e participar da construção do processo político. Trata-se, portanto, de pensar esse processo a partir do princípio do acesso universal consoante abordado no tópico que segue.

\section{A acessibilidade como pressuposto para a concretização dos direitos fundamentais das pessoas com deficiência}

A proteção e promoção dos direitos fundamentais das pessoas com deficiência constituem condições de possibilidade para a sua adequada inserção e participação na vida em sociedade. Nesse sentido, tanto Estado quanto comunidade devem propiciar a tutela adequada dos seus direitos, eliminando barreiras e obstáculos que dificultam a inclusão social. Isto porque a inadequada tutela desses direitos leva à marginalização e à exclusão, aumentando ainda mais os estigmas discriminatórios que essas pessoas têm sofrido ao longo da história.

Embora o Brasil seja um dos poucos países do mundo que têm uma legislação específica para esse grupo, continuam as pessoas com deficiência a compor as percentagens mais elevadas das estatísticas de exclusão social.

É esse cenário de diversas dificuldades que impõe, ao Estado e à sociedade, a concessão de uma atenção especial aos direitos das pessoas com deficiência, porquanto se trata de parcela extremamente vulnerável da sociedade e que, desde muito tempo, sofreu — e ainda sofre - com preconceitos e discriminações em razão de sua condição. É por isso que o reconhecimento dos seus direitos, em conjunto com a implementação de políticas públicas que visem proteger e promover sua inserção social, é de extrema relevância.

Apesar das dificuldades intrínsecas à sua condição, a preocupação da sociedade e do poder público com os direitos dessa camada da sociedade não data de muito tempo. Piovesan (2013:296) relata que a história da construção dos direitos humanos desses indivíduos compreende quatro fases: num primeiro momento, predominava a intolerância, a deficiência simbolizava impureza, pecado, castigo divino. Posteriormente, houve uma fase marcada pela invisibilidade dessas pessoas e, num terceiro momento, um estágio orientado por uma ótica 
assistencialista, pautada na perspectiva médica e biológica de que a deficiência era uma "doença a ser curada".

A quarta e atual fase é orientada pelo paradigma dos direitos humanos, na qual emergem os direitos à inclusão social. Trata-se de uma mudança de perspectiva, que aponta para o dever do Estado na eliminação de obstáculos que impeçam o pleno exercício dos direitos desse grupo: “de 'objeto' de políticas assistencialistas e de tratamentos médicos, as pessoas com deficiência passam a ser concebidas como verdadeiros sujeitos, titulares de direitos" (Piovesan, 2012:296).

É sob esse novo paradigma que, em 13 de dezembro de 2006, a Organização das Nações Unidas (ONU) adota a Convenção sobre os Direitos das Pessoas com Deficiência, nos termos da Resolução da Assembleia Geral no 61/2006. Trata-se, consoante Piovesan (2013: 297), de uma resposta da comunidade internacional à longa história de discriminação desses indivíduos, funcionando como um relevante instrumento "para a alteração da percepção da deficiência, reconhecendo que todas as pessoas devem ter a oportunidade de alcançar de forma plena o seu potencial" (Piovesan, 2013:297).

O Brasil é signatário da Convenção Internacional sobre os Direitos das Pessoas com Deficiência, promulgada pelo Decreto nº 6.949, de 25 de agosto de 2009. Este tratado, que ingressou no ordenamento jurídico brasileiro com status de emenda constitucional, conforme o procedimento do $\S 3^{\circ}$ do art. 5ำ da Constituição, estabelece no art. 1ํㅡㄴ como propósito, "promover, proteger e assegurar o exercício pleno e equitativo de todos os direitos humanos e liberdades fundamentais por todas as pessoas com deficiência e promover o respeito pela sua dignidade inerente" (Organização..., 2006).

A Convenção apresenta uma definição inovadora de deficiência, reconhecendo que o próprio meio ambiente econômico e social pode ser causa ou fator de agravamento da deficiência. Nesse sentido, e conforme reconhece a própria Convenção, a deficiência é um conceito em construção, que resulta da interação entre indivíduos com restrições e barreiras que impedem a plena e efetiva participação na sociedade em igualdade com os demais (Piovesan, 2013:297).

No dizer de Amita (2008:46-50), o fato de, anteriormente à Convenção, inexistir um regime de direitos políticos e civis para pessoas com deficiência contribuiu para que a abordagem assistencialista predominasse nas questões relativas ao tema. Com a Convenção, passou-se a reconhecer o direito à vida das pessoas com deficiência em pé de igualdade com os demais seres humanos.

Consoante Piovesan (2013:297-298), na medida em que o propósito da Convenção é promover, proteger e assegurar o pleno exercício dos direitos humanos das pessoas com deficiência, os Estados-partes são obrigados a tomar medidas legislativas, administrativas e de outras naturezas para a implementação dos direitos nela previstos. Assim, a Convenção aponta o dever do Estado de adotar ajustes, adaptações, ou modificações razoáveis e apropriadas para assegurar às pessoas com deficiência o exercício dos direitos humanos em igualdade de condições com as demais.

Com o ingresso da Convenção sobre os Direitos das Pessoas com Deficiência no ordenamento jurídico interno, o Brasil se obriga a discutir e promover, de maneira ainda mais 
acentuada, os direitos dessa camada social, indo ao encontro do que, desde 1988, já preceitua a Constituição da República Federativa do Brasil.

A proteção dos direitos fundamentais das pessoas com deficiência está, dentro dessa lógica, diretamente relacionada com a promoção e proteção da sua dignidade humana, expressamente prevista na Constituição como fundamento da República Federativa do Brasil, na medida em que é pelo reconhecimento desses indivíduos como sujeitos de direitos que se dará sua plena e efetiva inclusão na sociedade.

Nesse sentido, a proteção e promoção dos direitos das pessoas com deficiência acarretam o surgimento de obrigações concretas ao poder público, que deve assegurar a dignidade das pessoas com deficiência por meio de medidas positivas, que garantam sua integração social de maneira igualitária.

Assim, tendo em vista que a Convenção reconhece a necessidade de promover e proteger os direitos humanos de todas as pessoas com deficiência, a fim de que elas possam exercer sua autonomia e independência individuais, bem como ter a oportunidade de participar ativamente das decisões relativas a programas e políticas, inclusive aos que lhes dizem respeito diretamente (Organização..., 2006), um aspecto primordial a ser considerado na elaboração e implementação das políticas de governo eletrônico é a preocupação com o acesso adequado para as pessoas com deficiência.

Nesse sentido, a Convenção se preocupa, no art. 15, com a promoção da acessibilidade, determinando que os Estados-partes tomem medidas apropriadas para assegurar às pessoas com deficiência o acesso, em igualdade de oportunidades com os demais, ao meio físico, ao transporte, à informação e comunicação, às novas tecnologias da informação e comunicação (Organização..., 2006).

Contudo, consoante Vereza (2008:98-99), embora a Constituição Federal de 1988 seja um importante marco na garantia dos direitos específicos das pessoas com deficiência, uma análise atenta revela que os avanços legais, tecnológicos e a formulação de políticas estão longe da maioria desses indivíduos. Na prática, a efetivação da cidadania plena e da inclusão social das pessoas com deficiência ainda não é garantida.

O exercício da participação política dos cidadãos, como expressão da cidadania, deve ser propiciado de maneira ampla pelo Estado. Desse modo, percebe-se que a participação das pessoas com deficiência só será possível caso garantam-se os meios necessários para que esses indivíduos possam exercer seus direitos de cidadão em plenitude. De outro modo, o discurso de participação ficará relegado a um aspecto meramente formal, sem se preocupar com as diferentes realidades e contextos de cada um. É tendo em vistas essas questões que, quando se aborda o desenvolvimento das políticas de governo eletrônico, é fundamental a preocupação com a questão da acessibilidade digital, conforme abordado no tópico a seguir.

\section{A utilização das TICs pela administração pública e a acessibilidade digital}

A utilização da tecnologia como forma de empoderamento social pode ter impactos políticos bastante positivos, especialmente em camadas já marginalizadas da sociedade. Nesse sentido, 
a apropriação que o Estado brasileiro faz das tecnologias informacionais deve direcionar especial atenção às pessoas com deficiência, devendo a política de acessibilidade não ser pensada somente em relação ao espaço físico, mas também à esfera digital.

Apesar das determinações advindas tanto de tratados internacionais quanto de leis ordinárias, a inclusão das pessoas com deficiência ainda é uma área bastante delicada. Para Kasinskaite-Buddeberg (2013:52), o uso das TICs por esses sujeitos não é prioridade em agendas políticas, e o acesso à informação por meio do uso das TICs não é reconhecido como um dos requisitos básicos para o cumprimento dos direitos humanos fundamentais.

Para algumas pessoas, as ajudas técnicas atuam como complemento, enquanto para outras são imprescindíveis, sendo por meio delas que conseguem se expressar. Para estas, é a tecnologia que realiza a intermediação da sua comunicação com o mundo. Por isso, é importante ter em mente que nem tudo que é divulgado na forma digital vai ser recebido pelo usuário, se não foi pensado o aspecto da acessibilidade a essa informação, no momento em que se concebeu o seu conteúdo (Torres, Mazzoni e Alves, 2002:87). No caso das pessoas com deficiência, as limitações dificultam e em alguns casos até mesmo impossibilitam o acesso à internet. Em razão disso, são desenvolvidas tecnologias assistivas, como navegadores por voz ou que apenas apresentem texto.

A acessibilidade no espaço digital consiste em tornar disponível ao usuário, de forma autônoma e independente de suas características, toda a informação que lhe for franqueável, sem prejuízos quanto ao conteúdo da informação. Essa acessibilidade é obtida combinando-se a apresentação da informação de formas múltiplas, seja por meio de uma simples redundância - por exemplo, a existência de um equivalente textual para os conteúdos divulgados por meio de imagens ou de sons — - seja por meio de um sistema automático de transcrição de mídias, com o uso de ajudas técnicas (sistemas de leitura de tela, sistemas de reconhecimento da fala, simuladores de teclado etc.) que maximizam as habilidades dos usuários que possuem limitações associadas a deficiências (Torres, Mazzoni e Alves, 2002:85).

Nesse sentido, o desenvolvimento de sites governamentais deve ser pensado de forma a atender critérios de acessibilidade que garantam a possibilidade de as pessoas com deficiência utilizarem o conteúdo disponível no local. Na medida em que a tecnologia permite a inserção mais qualificada das pessoas com deficiência na sociedade, a existência de sites governamentais acessíveis possibilita que esses sujeitos tenham as condições necessárias para participar de maneira mais ativa da esfera pública. Assim, verifica-se como a elaboração de sites acessíveis está diretamente relacionada com uma melhor inclusão desse grupo social na política do Estado.

Para desenvolvimento de um site acessível, existem diretrizes de acessibilidade que explicam como criar uma página que possa ser acessada por todas as pessoas. Um dos principais documentos nessa área é a WCAG, elaborada pelo W3C (World Wide Web Consortium) um consórcio de âmbito internacional com a finalidade de desenvolver especificações, guias e ferramentas para a web —, que traz diversas recomendações com a finalidade de tornar o conteúdo mais acessível. Esses padrões de desenvolvimento web definidos pelo W3C são um conjunto de recomendações que visa padronizar o conteúdo das páginas, possibilitando melhores práticas na sua elaboração. Após a criação da página, é possível testar sua acessibilidade, 
o que pode ser feito por meio de um validador automático disponibilizado pelo próprio W3C. Validadores são softwares ou serviços on-line que ajudam a determinar se um site respeitou ou não as recomendações de acessibilidade, gerando um relatório de erros (Brasil, 2011a:9-10).

No caso do Brasil, o Executivo federal tem concedido certa atenção à implementação do governo eletrônico em consonância com as necessidades das pessoas com deficiência. O documento de referência, neste campo, é a cartilha e-MAG: Modelo de Acessibilidade em Governo Eletrônico (Brasil, 2011), atualmente na versão 3.0, elaborada pelo Departamento de Governo Eletrônico, vinculado à Secretaria de Logística e Tecnologia da Informação do Ministério do Planejamento, Orçamento e Gestão, e que foi desenvolvida tendo por base os padrões de acessibilidade da W3C. Esse documento define o modelo de acessibilidade do governo eletrônico na administração pública federal, buscando assim facilitar o acesso para todas as pessoas às informações e serviços disponibilizados nos sites e portais do governo.

Consoante a Cartilha (Brasil, 2011:7-8), as quatros principais situações vivenciadas pelas pessoas com deficiência no acesso ao computador são: a) acesso ao computador sem mouse: no caso de pessoas com deficiência visual, dificuldade de controle dos movimentos, paralisia ou amputação de um membro superior; b) acesso ao computador sem teclado: no caso de pessoas com amputações, grandes limitações de movimentos ou falta de força nos membros superiores; c) acesso ao computador sem monitor: no caso de pessoas com cegueira; d) acesso ao computador sem áudio: no caso de pessoas com deficiência auditiva.

Contudo, é importante analisar que esses não são os únicos casos que devem ser considerados quando se trata de acessibilidade na $w e b$, pois existem diversas pessoas com limitações relacionadas com a memória, resolução de problemas, atenção, compreensão verbal, leitura e linguística, compreensão matemática e compreensão visual. Em face disto, um site desenvolvido considerando a acessibilidade deve englobar diferentes níveis de escolaridade, faixa etária e pouca experiência na utilização do computador, bem como ser compatível com as diversas tecnologias utilizadas para acessar uma página da web. As tecnologias assistivas auxiliam na navegação das páginas, possibilitando autonomia e independência às pessoas com deficiência; contudo, apenas o uso dessas tecnologias não garante, por si só, o acesso ao conteúdo de um site, porque, para tanto, é necessário que a página tenha sido desenvolvida de maneira acessível (Brasil, 2011:8).

Em razão disso, a Cartilha e-MAG traz recomendações para que a implementação da acessibilidade nos sites do governo brasileiro seja realizada de forma padronizada e coerente com as necessidades dos internautas. Destacam-se algumas das recomendações presentes na Cartilha e-MAG, tais como: ordenar de forma lógica e intuitiva a leitura e tabulação; identificar o idioma principal da página; fornecer alternativa em texto para as imagens do site; disponibilizar documentos em formatos acessíveis, preferencialmente em HTML; oferecer contraste mínimo entre plano de fundo e primeiro plano; permitir fácil leitura e redimensionamento de texto sem perda de funcionalidade; fornecer alternativa para áudio; estabelecer uma ordem lógica de navegação; dentre diversas outras (Brasil, 2011:13-58).

Outro ponto que merece destaque na Cartilha é a indicação de elementos de acessibilidade que devem ser padronizados nos sites do Executivo federal, a fim de facilitar o acesso, 
garantindo o desenvolvimento de páginas acessíveis a todas as pessoas. Os elementos que devem estar presentes em todas as páginas do governo federal são: a) página com a descrição dos recursos de acessibilidade; b) teclas de atalho; c) barra de acessibilidade; d) apresentação do mapa do site; e) apresentação de formulário; f) conteúdo alternativo para imagens; g) apresentação de documentos (Brasil, 2011:59).

Essa padronização mínima, estabelecida pela Cartilha e-MAG, delineou os critérios utilizados na observação estruturada realizada na parte seguinte do trabalho.

\section{A acessibilidade nos portais do Poder Executivo estadual: um estudo comparado dos sites dos estados de São Paulo, Rio de Janeiro, Minas Gerais, Rio Grande do Sul, Paraná, Bahia, Distrito Federal e Santa Catarina}

Análises prévias sobre o tema indicam que a preocupação com a acessibilidade ainda encontra fraca presença nos sites governamentais. Em estudo sobre a acessibilidade nos portais dos governos estaduais entre 1996 e 2007, Freire, Castro e Fortes (2009:412) constaram que o atendimento aos critérios de acessibilidade em órgãos públicos ainda não era satisfatório no período pesquisado. Em outro estudo, Bach e colaboradores (2009:83), ao analisarem a acessibilidade de 87 sites de diferentes organizações brasileiras, constataram que apenas $47 \%$ deles continham ferramentas de acessibilidade em consonância com o previsto na Cartilha E-Mag e nas diretrizes do WCAG.

Mais recentemente, Alves e colaboradores (2012:10-11), ao realizarem um panorama da acessibilidade dos 27 sites dos Legislativos estaduais, a partir da avaliação de cada um deles com a utilização da ferramenta DaSilva (que avalia o nível de acessibilidade das páginas pesquisadas, dentro das regras preconizadas pelo E-Mag), avaliaram que nenhuma das páginas pesquisadas estava apta a receber o selo de acessibilidade. Verifica-se, desse modo, que é uma área na qual ainda há muito que avançar.

A partir dos delineamentos da Cartilha e-MAG, este último tópico tem por objeto um estudo comparado da aplicação das ferramentas de acessibilidade em determinados sites oficiais — os denominados portais - dos estados da República Federativa do Brasil. Embora a Cartilha tenha sido elaborada pelo Poder Executivo federal, determinando sua observância nos sites da União, entende-se que as recomendações mínimas de acessibilidade são necessárias para quaisquer portais governamentais, independentemente da esfera de poder, uma vez que os demais poderes, tanto estaduais quanto municipais, devem garantir o acesso a todo e qualquer cidadão, independentemente de condição física, psíquica ou econômica. Por esse motivo, parte-se do princípio de que a utilização destes elementos de padronização como critérios de análise também deve ser observada pelos demais poderes, sendo assim adequada a transposição dos requisitos mínimos da Cartilha para verificação da acessibilidade em outros sites.

Além disso, deve ser ressaltado que esses são os requisitos mínimos para a garantia da acessibilidade. No caso deste estudo, cuja análise é voltada para pessoas com deficiência, além desses requisitos, outros softwares necessitarão ser utilizados em conjunto, tais como leitores 
de tela etc. Contudo, ao menos esses elementos devem estar presentes para que um mínimo de acessibilidade seja garantido às pessoas com deficiência.

Nesse sentido, o objeto de estudo recaiu sobre os sites do Poder Executivo estadual de determinados estados da federação, com o objetivo de verificar se atendem aos critérios mínimos de acessibilidade. Na avaliação, efetuada pelos próprios autores do trabalho, efetuou-se o cotejo entre as determinações da Cartilha e-MAG com a realidade observada nos portais dos estados selecionados, utilizando a técnica de observação direta, sistemática e não participante nos sites mencionados, realizada no mês de novembro de 2013, a partir da observação da existência ou não dos elementos de acessibilidade delineados na Cartilha e-MAG.

Tendo por base o método utilizado por Santos, Bernardes e Rover (2012:61-66), que emprega a elaboração de formulários com perguntas fechadas, foi elaborado o formulário estruturado on-line por meio da plataforma Google Drive, contendo, de forma sistematizada, as categorias de análise.

Como critério de delimitação, foram selecionados os oito estados da federação com maior participação no Produto Interno Bruto (PIB) brasileiro, consoante estatísticas do Instituto Brasileiro de Geografia e Estatística (IBGE), na última pesquisa "Contas Regionais do Brasil" divulgada pelo órgão, que abrange o período de 2005 a 2009. Nesse estudo, os oito estados com maior percentual de participação (cerca de 80\%) do PIB brasileiro, no ano de 2009, são, do primeiro ao oitavo lugar, respectivamente: São Paulo, Rio de Janeiro, Minas Gerais, Rio Grande do Sul, Paraná, Bahia, Distrito Federal e Santa Catarina (Brasil, 2011b:24). A escolha pelo critério do PIB deveu-se ao entendimento de que os estados com melhores índices de desenvolvimento econômico possuem — em tese - melhores condições econômicas e estruturais para implantar recursos de acessibilidade em seus portais.

Em cada um dos portais estaduais desses estados foi analisada a presença dos itens da Cartilha e-MAG: a) página com a descrição dos recursos de acessibilidade; b) teclas de atalho; c) barra de acessibilidade; d) apresentação do mapa do site; e) apresentação de formulário para contato; f) conteúdo alternativo para imagens; g) apresentação de documentos.

Inicialmente, verificou-se que, nos oito portais analisados, não há, na página inicial, nenhum banner ou chamada específica para a questão da acessibilidade que dê grande destaque à questão. No máximo, o que existe, em alguns sites, é a barra de acessibilidade, de forma discreta, na parte superior da página. Percebe-se, portanto, que o tema da acessibilidade é tratado de forma discreta nesses portais.

O primeiro item (o site apresenta página com a descrição dos recursos de acessibilidade) refere-se à existência de seção na qual deveriam ser apresentados os recursos de acessibilidade presentes no site, tais como teclas de atalho disponíveis, opções de redimensionamento de texto e alto contraste, detalhes sobre testes de acessibilidade e outras informações pertinentes (Brasil, 2011:59). Em relação a esse primeiro ponto, observou-se que, dos oito portais analisados, apenas dois estados — Minas Gerais e Paraná — apresentavam página descrevendo recursos de acessibilidade disponíveis no portal. No caso do Paraná, é interessante observar que, nessa seção sobre acessibilidade, constavam, além de informações gerais, dados 
complementares sobre leitores de tela, suas funções e links para realizar downloads gratuitos de softwares para tanto.

Figura 1

O site apresenta página com a descrição dos

recursos de acessibilidade?

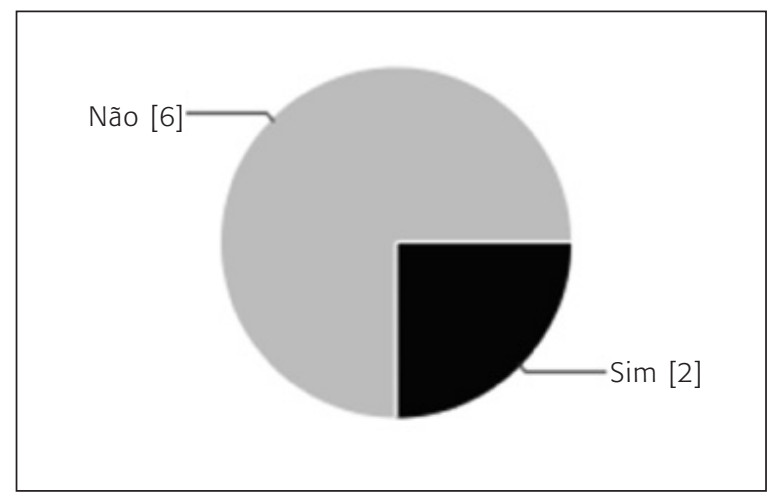

Fonte: Elaborada pelo autor utilizando a ferramenta Google Drive.

Sim $225 \%$

Não $\quad 6 \quad 75 \%$

Os demais, embora em alguns casos apresentem certas ferramentas de acessibilidade, não possuem propriamente uma seção no portal destinada a tratar do assunto, que conte com informações sobre política de acessibilidade. Este resultado já é um primeiro indício da ausência de preocupação com a política de acessibilidade.

O segundo ponto refere-se à existência de atalhos por teclado que, conforme a Cartilha e-MAG, devem ser disponibilizados para pontos estratégicos da página, permitindo que o usuário possa ir diretamente a esses pontos, devendo funcionar por meio de números precedidos da tecla padrão de cada navegador, bem como as dicas dos atalhos devem estar explicitadas na barra de acessibilidade (Brasil, 2011:60-61). Novamente, foram verificados apenas em Minas Gerais e no Paraná, ou seja, nos mesmos portais com seções específicas destinadas aos recursos de acessibilidade. Os demais sites não mencionavam a existência de teclas de atalho disponíveis.

O terceiro item, relativo à existência de barra de acessibilidade, apontou melhores resultados: das oito unidades da federação, seis possuem portais com estas barras: São Paulo, Rio de Janeiro, Minas Gerais, Paraná, Distrito Federal e Santa Catarina, ficando de fora Rio Grande do Sul e Bahia. A barra de acessibilidade é importante por, já logo que o indivíduo acessa o site, mostrar quais as ferramentas de acessibilidade estão disponíveis, dando destaque aos recursos existentes. Sua ausência, portanto, sinaliza que dificilmente serão encontradas ferramentas de acessibilidade ao longo das diferentes seções do site. 
Figura 2

O site apresenta teclas de atalho?



Fonte: Elaborada pelo autor utilizando a ferramenta Google Drive.

$\operatorname{sim} 225 \%$

Não $6 \quad 75 \%$

Figura 3

O site apresenta barra de acessibilidade?

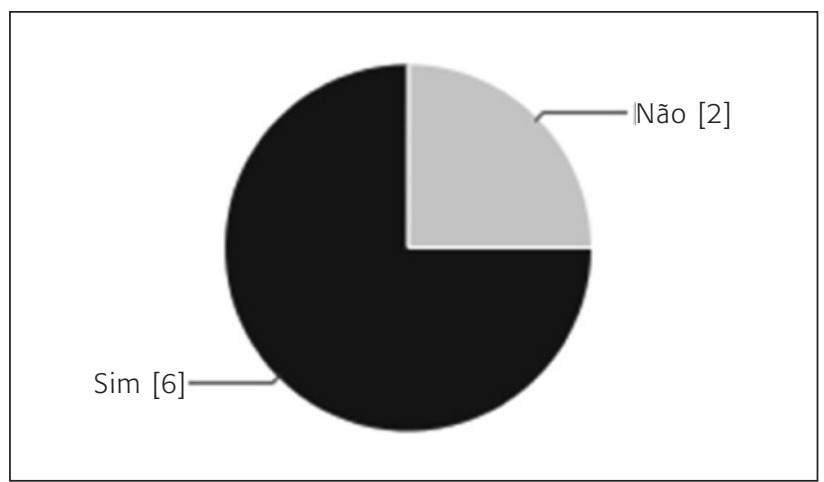

Fonte: Elaborada pelo autor utilizando a ferramenta Google Drive.

Sim $675 \%$

Não $2 \quad 25 \%$

No que tange ao quarto item (quais itens constam na barra de acessibilidade), como Rio Grande do Sul e Bahia não apresentavam barra de acessibilidade, essa análise ficou prejudicada. No caso do Rio Grande do Sul, embora não exista barra de acessibilidade na página inicial do site, ao clicar nos links para as diferentes seções, surge a ferramenta de aumento ou diminuição de fonte em cada página específica. Contudo, além de ser a única existente, o fato de estar na segunda camada de acesso, e não na página inicial, já compromete sua funcionalidade, pois o cidadão que necessita de uma fonte maior sequer conseguirá compreender a primeira página do site. 
Figura 4

Quais os itens a seguir constam na barra de acessibilidade?



Fonte: Elaborada pelo autor utilizando a ferramenta Google Drive.

$\begin{array}{lll}\text { Aumentar fonte } & 6 & 21 \%\end{array}$

$\begin{array}{lll}\text { Diminuir fonte } & 5 & 18 \%\end{array}$

$\begin{array}{lll}\text { Fonte normal } & 4 & 14 \%\end{array}$

$\begin{array}{lll}\text { Alto contraste } & 4 & 14 \%\end{array}$

Atalhos para menu, conteúdo e busca $\quad 5 \quad 18 \%$

Acessibilidade (link para a página contendo os recursos de acessibilidade do sítio) $2 \quad 7 \%$

$\begin{array}{lll}\text { Não apresenta esta barra } & 2 & 7 \%\end{array}$

Em relação aos que apresentam barra de acessibilidade, todos os seis, São Paulo, Rio de Janeiro, Minas Gerais, Paraná, Distrito Federal e Santa Catarina, apresentam ferramenta de redimensionamento da fonte (aumento e diminuição), o Paraná apresenta somente de aumento e de fonte normal, assim como Rio de Janeiro, Distrito Federal e Santa Catarina também apresentam a possibilidade de retorno à fonte normal. A ferramenta de contraste é encontrada somente em quatro sites: São Paulo, Rio de Janeiro, Minas Gerais e Paraná; enquanto a ferramenta atalhos para menu, conteúdo e busca foi encontrada em cinco sites: São Paulo, Rio de Janeiro, Minas Gerais, Paraná e Santa Catarina. Por fim, a existência da "acessibilidade", ou seja, link para a página contendo os recursos de acessibilidade do site, foi encontrada nos portais de Minas Gerais e Paraná, ou seja, os únicos que apresentavam página descrevendo recursos de acessibilidade disponíveis no portal.

O mapa do site, cuja função é apresentar as páginas internas não presentes no menu inicial, orientando o cidadão acerca da estrutura do portal, pode ser observado nos seguintes portais: Rio Grande do Sul, Rio de Janeiro, Minas Gerais, Paraná, Distrito Federal e Santa Catarina, ficando de fora, portanto, São Paulo e Bahia. Embora Minas Gerais apresente mapa 
do site, ao clicar nessa seção, não era possível visualizar o mapa, o que leva a crer que o link não estava funcionando.

\section{Figura 5}

O site apresenta o mapa do site?

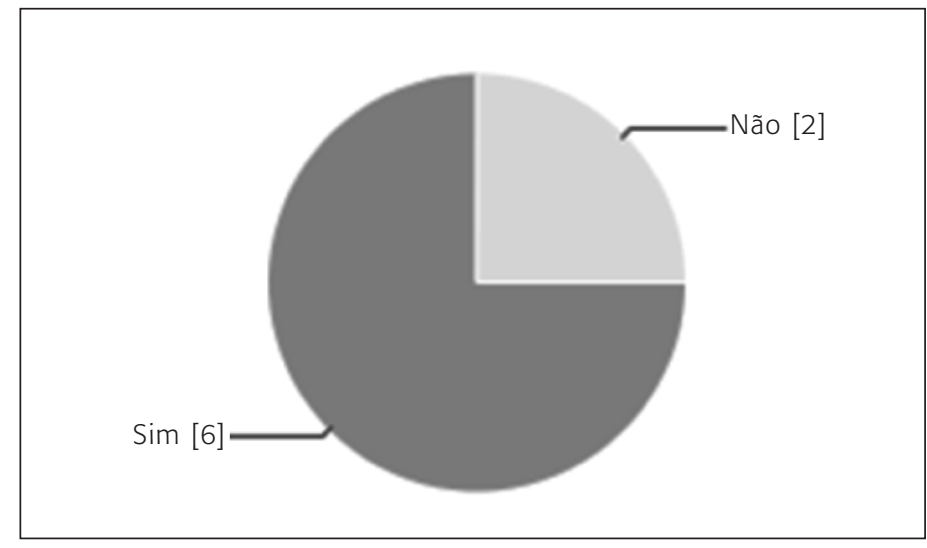

Fonte: Elaborada pelo autor utilizando a ferramenta Google Drive.

$\operatorname{Sim} 675 \%$

Não $225 \%$

Em relação à existência de formulário para contato, cuja finalidade é permitir ao cidadão entrar em contato com a administração pública, verificou-se a sua existência em cinco portais: São Paulo, Minas Gerais, Paraná, Bahia e Santa Catarina, estando ausente nos portais do Rio Grande do Sul, Rio de Janeiro e Distrito Federal. No que diz respeito à Bahia, apesar da existência, o formulário encontra-se em seção própria da ouvidoria, o que não parece o mais adequado, uma vez que o cidadão pode não ter o conhecimento técnico específico acerca da função de uma ouvidoria e, assim, não se dar conta de que deve utilizar o link da ouvidoria para encaminhar mensagens ao poder público.

No que tange ao Rio Grande do Sul, embora o portal não apresente formulário próprio para contato, possui uma seção específica direcionando para os sites de cada Secretaria Estadual, as quais, por vezes, apresentam formulário específico para contato. Semelhante é o caso do Distrito Federal, no qual o próprio portal não apresenta formulário. Para entrar em contato com o governo estadual, é necessário entrar nos links específicos das Secretarias e demais órgãos estaduais, e a partir daí acessar o formulário específico. Essa ausência no próprio site do governo estadual é prejudicial aos cidadãos, uma vez que impede o contato direito com o governo estadual - muitas vezes, é necessário o contato direto com o Executivo, e não com alguma secretaria. A ausência de um meio eletrônico bastante direto e prático como é o formulário configura-se, desse modo, prejudicial à comunicabilidade com os cidadãos. 
Figura 6

O site apresenta formulário?

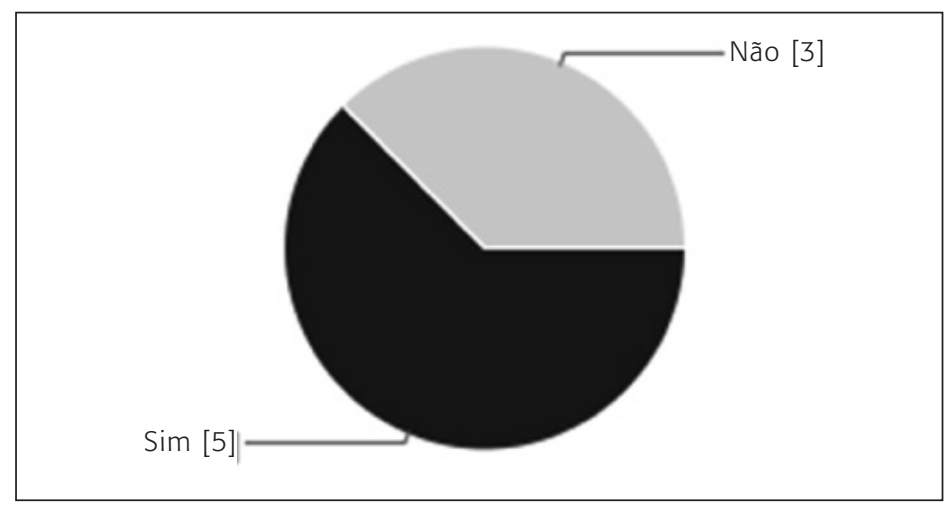

Fonte: Elaborada pelo autor utilizando a ferramenta Google Drive.

$\operatorname{Sim} 563 \%$

Não $3 \quad 38 \%$

O sétimo item, que questiona a existência de conteúdo alternativo para imagens, teve resposta negativa nos oito portais. A existência de alternativa textual para as imagens é relevante porque os sistemas atuais não têm capacidade de analisar e determinar o que uma imagem representa no contexto de uma página. Assim, o conteúdo de uma imagem deve ser determinado, para que os leitores de tela utilizados por pessoas portadoras de deficiência visual possam traduzir o conteúdo da imagem. Nesse sentido, verifica-se que os sites pecam ao não propiciar alternativas às imagens, dificultando o acesso às pessoas com deficiência.

\section{Figura 7}

O site apresenta conteúdo alternativo para imagens?

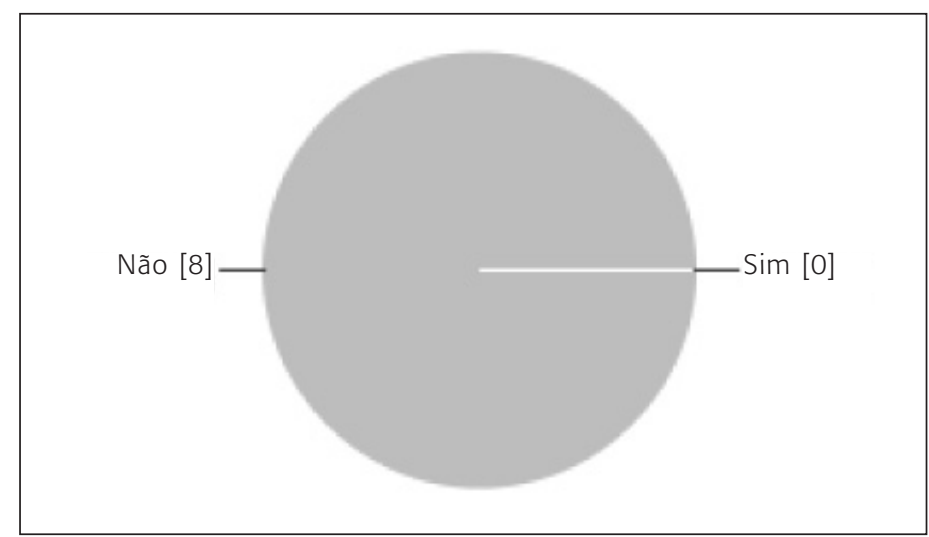

Fonte: Elaborada pelo autor utilizando a ferramenta Google Drive.

$\operatorname{Sim} 0 \%$

Não $8 \quad 100 \%$ 
Por fim, o oitavo item (em que formatos estão disponibilizados os documentos do site) apontou que todos os portais apresentavam praticamente todo o conteúdo em HTML, o que está de acordo com a previsão da Cartilha e-MAG. Alguns estados, como Rio Grande do Sul e Rio de Janeiro, apresentavam documentos em PDF, contudo, o que predominou foi a presença do HTML. Esses documentos referem-se aos documentos da administração pública de modo amplo, ou seja, dados relativos a licitações, contratos, organograma, competências e atribuições dos órgãos, auditorias, prestações de contas, dentre outros.

Figura 8

\section{Em que formatos são disponibilizados os documentos do site?}

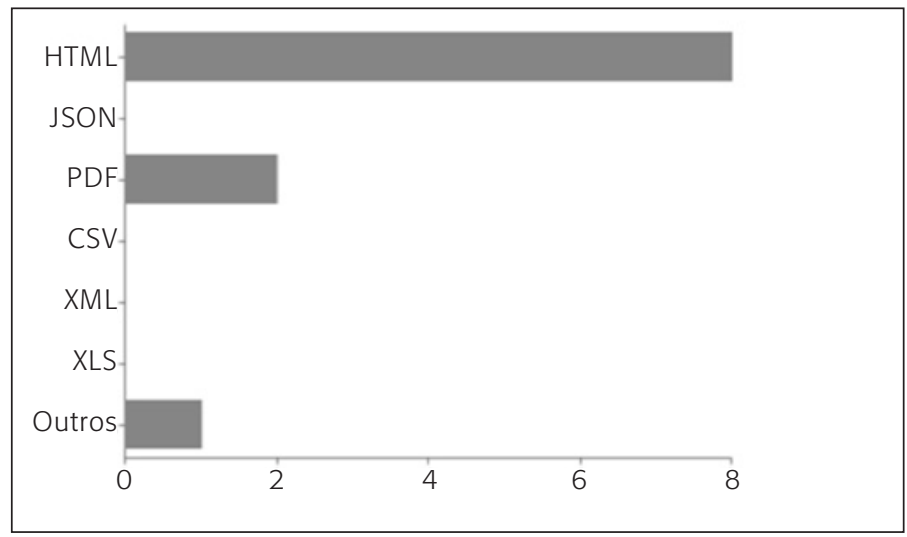

Fonte: Elaborada pelo autor utilizando a ferramenta Google Drive.

$\begin{array}{llr}\text { HTML } & 8 & 73 \% \\ \text { JSON } & 0 & 0 \% \\ \text { PDF } & 2 & 18 \% \\ \text { CSV } & 0 & 0 \% \\ \text { XML } & 0 & 0 \% \\ \text { XLS } & 0 & 0 \% \\ \text { Outros } & 1 & 9 \%\end{array}$

Como a maior parte do conteúdo é em formato textual, seria interessante que os sites disponibilizassem conteúdo alternativo, como em vídeos ou áudios, de forma a possibilitar que pessoas com deficiência, como alguém com deficiência visual, tenha outro modo de acessar a mensagem. Contudo, essa funcionalidade não foi percebida nas páginas pesquisadas.

Torres, Mazzoni e Alves (2002:83) destacam que o espaço digital possibilita apresentar a informação de modo amplo, razão pela qual é importante que essa possibilidade seja explorada para garantir a acessibilidade aos conteúdos. Contudo, o que se verifica da observação efetuada neste estudo é que os sites governamentais ainda não estão sendo desenvolvidos com uma preocupação relevante no que diz respeito a tornar suas páginas acessíveis. Embora alguns portais apresentem algumas ferramentas, a impressão que fica é que a acessibilidade 
dos sites governamentais ainda é uma preocupação menor, que não toma muito tempo no planejamento e desenvolvimento das páginas.

Infelizmente, a preocupação com a utilização de portais de governo de forma ampla e acessível a toda e qualquer pessoa não deveria ser vista como algo a ficar em segundo plano. Especificamente em relação às pessoas com deficiência, a inclusão digital caminha em paralelo à inclusão social. Na sociedade que se vive atualmente, não há como se pensar em inclusão efetiva na sociedade sem considerar a necessidade do acesso à internet e, no caso em questão, a possibilidade de conseguir acessar o conteúdo disponibilizado pelos órgãos governamentais. Hoje, boa parte do conteúdo que a administração pública disponibiliza está na web — e, em alguns casos, somente na web, pois não raro na própria repartição física as pessoas são aconselhadas a buscar determinados formulários e documentos nos sites governamentais. Nesse sentido, não facilitar o acesso às pessoas com deficiência é alijá-las deste processo de aceleração tecnológica sem precedentes propiciado pela internet e, em consequência, excluí-las da possibilidade de um exercício da cidadania de forma mais ampla e efetiva.

Frise-se que os pontos analisados nos sites dos Executivos estaduais foram bastante pontuais, tendo como referência as padronizações mínimas exigidas na Cartilha e-MAG. Quer dizer, a existência dessas ferramentas seria o mínimo para que as pessoas com deficiência pudessem navegar de forma adequada nos portais governamentais, sem excluir a necessidade de utilização de outros programas. Ocorre que, se sequer as exigências mínimas são observadas, a inclusão se torna extremamente difícil.

É importante considerar que a visão das tecnologias deve ser realizada por um enfoque mais amplo, ou seja, a tecnologia não como a meta final, mas sim como um dos caminhos para atingir a igualdade. Se a tecnologia tem um potencial de democratização da participação política das pessoas com deficiência, para que essa participação seja efetiva, é imprescindível que os sites governamentais sejam acessíveis, contendo ferramentas que facilitem a navegação e permitam, tanto quanto possível, a superação das barreiras e obstáculos que impedem o pleno acesso.

Ora, consoante já mencionado na primeira parte deste trabalho, a tecnologia por si mesma não resolverá os problemas de participação política. De nada basta o desenvolvimento de portais governamentais se estes não forem implantados com políticas de acessibilidade amplas e eficientes, que permitam às pessoas com deficiência o acesso ao seu conteúdo.

\section{Conclusão}

A expansão do governo eletrônico vem abrindo debates relativos a novas expressões de cidadania e participação da sociedade civil. Contudo, o potencial democrático das TICs somente terá reais perspectivas de concretização caso o governo eletrônico seja pensado sob uma ótica que leve em consideração as diferentes realidades culturais, sociais, políticas e econômicas da sociedade brasileira, a exemplo das dificuldades enfrentadas pelas pessoas com deficiência. 
Por isso, a implementação de sites governamentais deve necessariamente passar pela questão da acessibilidade digital. A tecnologia pode funcionar como um meio para atingir a igualdade material, tendo como meta a inclusão política das pessoas com deficiência, pois, acessando sites governamentais acessíveis, é possível trazer a informação e a comunicação e, como consequência, a participação política dessas pessoas.

Apesar de alguns avanços nessa área, como a elaboração, pelo Governo Federal, da Cartilha e-MAG, que determina padrões mínimos de acessibilidade digital, no caso dos Executivos estaduais, a preocupação ainda parece pequena. $\mathrm{Na}$ análise realizada neste artigo, que contrastou a realidade dos sites estaduais com as determinações previstas na Cartilha, observou-se que pouco tem sido implementado em matéria de acessibilidade. Apesar das determinações constitucionais, advindas da Carta Magna e da Convenção, o reflexo ainda é inexpressivo nos sites e portais dos governos estaduais analisados.

Dos oito portais pesquisados (São Paulo, Rio de Janeiro, Minas Gerais, Rio Grande do Sul, Paraná, Bahia, Distrito Federal e Santa Catarina), nenhum contemplou de maneira plena os padrões mínimos da Cartilha. O destaque ficou por conta de Minas Gerais e Paraná, que apresentavam em seus sites a maioria dos itens observados, enquanto Rio Grande do Sul e Bahia foram os destaques negativos, por apresentar pouquíssimas ferramentas de acessibilidade - sequer barra de acessibilidade, contendo ferramentas simples como aumento/diminuição de fonte e contraste, foi observada. Como se vê, ainda há muito que avançar no caminho da acessibilidade digital.

De nada adianta um país afirmar que se preocupa com a situação das pessoas com deficiência, se não implementa as condições necessárias para que elas possam se afirmar como verdadeiros sujeitos de direito. É por isso que, ao mesmo tempo que se defende que o governo eletrônico traz a possibilidade de uma nova expressão de cidadania a esses indivíduos, entende-se que o primeiro passo é o planejamento e desenvolvimento de portais governamentais preocupados com a acessibilidade. Sem acessibilidade, sequer se pode falar em concretização dos direitos fundamentais de participação política das pessoas com deficiência, uma vez que o acesso é a primeira condição de possibilidade para a participação.

\section{Referências}

ALVES, Alan V.; DUARTE, Adriana B. S.; NEGREIROS, Leandro R. Informação e exclusão: o panorama da (in)acessibilidade dos portais legislativos estaduais. In: ENCONTRO NACIONAL DE PESQUISA EM CIÊNCIA DA INFORMAÇÃO, 13, 2012, Rio de Janeiro. Anais... Rio de Janeiro: Fiocruz, 2012.

AMITA, Dhanda. Construindo um novo léxico dos direitos humanos: convenção sobre os direitos das pessoas com deficiências. Sur — Revista Internacional de Direitos Humanos, v. 5, n. 8, p. 43-59, jun. 2008. Disponível em: <www.surjournal.org/conteudos/pdf/8/completo.pdf>. Acesso em: 4 dez. 2013. 
BACH, Catharine F. et al. Diretrizes de acessibilidade: uma abordagem comparativa entre WCAG e e-MAG. In: SIMPÓSIO BRASILEIRO DE SISTEMAS DE INFORMAÇÃO, V, 2009, Brasília. Anais... Brasília: Sociedade Brasileira de Computação, 2009. p. 73-74.

BAHIA. Governo da Bahia. Disponível em: <www.ba.gov.br/>. Acesso em: 4 dez. 2013.

BARBOSA, Alexandre F.; CUNHA, Maria A.; PINTO, Solon L. Governança eletrônica no setor público: o caso da institucionalização do programa de e-governo no Brasil. In: OLIVEIRA, Fátima B. de (Org.). Tecnologia da informação e comunicação: a busca de uma visão ampla e estruturada. São Paulo: Fundação Getulio Vargas, 2007. p. 179-195.

BRASIL. Constituição da República Federativa do Brasil: promulgada em 5 de outubro de 1988. Disponível em: <www.planalto.gov.br/ccivil_03/constituicao/constituicao.htm>. Acesso em: 4 dez. 2013.

BRASIL. Ministério do Planejamento, Orçamento e Gestão. Instituto Brasileiro de Geografia e Estatística. Contas regionais do Brasil 2005-2009. Rio de Janeiro, 2011b.

BRASIL. Ministério do Planejamento, Orçamento e Gestão. Secretaria de Logística e Tecnologia da Informação. e-MAG Modelo de acessibilidade em governo eletrônico. Brasília: MP; SLTI, 2011a.

BRASIL. Sociedade da informação no Brasil: livro verde. Organizado por Tadao Takahashi. Brasília: Ministério da Ciência e Tecnologia, 2000.

DISTRITO FEDERAL. Portal do Governo do Distrito Federal. Disponível em: <www.df.gov.br/> . Acesso em: 4 dez. 2013.

FREIRE, André P.; CASTRO, Mário de; FORTES, Renata P. de M. Acessibilidade dos sítios web dos governos estaduais brasileiros: uma análise quantitativa entre 1996 e 2007. Rev. Adm. Pública, Rio de Janeiro, v. 43, n. 5, p. 395-414, mar./abr. 2009.

GOMES, Wilson. A democracia digital e o problema da participação civil na decisão política. Revista Fronteiras - estudos midiáticos, v. 7, n. 3, p. 214-222, set./dez. 2005.

KASINSKAITE-BUDDEBERG, Irmgarda. Levando as TIC a pessoas com deficiência para seu empoderamento. In: BARBOSA, Alexandre F. (Coord.). Pesquisa sobre o uso das tecnologias de informação e comunicação no Brasil: TIC Domicílios e Empresas 2012. São Paulo: Comitê Gestor da Internet no Brasil, 2013. p. 51-64.

MINAS GERAIS. Governo do Estado de Minas Gerais. Disponível em: <www.mg.gov.br/>. Acesso em: 4 dez. 2013.

ORGANIZAÇÃO DAS NAÇÕES UNIDAS. Convenção sobre os direitos das pessoas com deficiência. 2006. Disponível em: <www.planalto.gov.br/ccivil_03/_ato2007-2010/2009/decreto/d6949. htm>. Acesso em: 4 dez. 2013.

PARANÁ. Estado do Paraná. Disponível em: <www.pr.gov.br>. Acesso em: 4 dez. 2013.

PEREZ LUÑO, Antonio-Henrique. Internet e los derechos humanos. Derecho y conocimiento, v. 2, p. 101-121. Disponível em: <http://dialnet.unirioja.es/servlet/articulo? codigo=995024\&orden= 25231\&info=link>. Acesso em: 7 ago. 2014. 
PIANA, Ricardo S. Gobierno electrónico: gobierno, tecnologías y reformas. La Plata: Universidad Nacional de La Plata, 2007.

PINHO, José A. G. de. Internet, governo eletrônico, sociedade e democracia no Brasil: algumas questões básicas em debate. Revista VeraCidade, v. 3, n. 3, p. 1-20, maio 2008.

PIOVESAN, Flávia. Direitos humanos e o direito constitucional internacional. 14. ed. São Paulo: Saraiva, 2013.

RIO DE JANEIRO. Portal do Governo do Estado do Rio de Janeiro. Disponível em: <www.rj.gov. br/>. Acesso em: 4 dez. 2013.

RIO GRANDE DO SUL. Portal do Estado do Rio Grande do Sul. Disponível em: <www.rs.gov.br/ lista/noticias>. Acesso em: 4 dez. 2013.

ROVER, Aires J. A democracia digital possível. Revista Sequência, v. 27, n. 52, p. 85-104, jul. 2006. Disponível em: <http://periodicos.ufsc.br/index.php/sequencia/article/view/15202/13827>. Acesso em: 4 dez. 2013.

SANTA CATARINA. Governo do Estado de Santa Catarina. Disponível em: <www.sc.gov.br/>. Acesso em: 4 dez. 2013.

SANTOS, Paloma M.; BERNARDES, Marciele B.; ROVER, Aires J. Teoria e prática de governo aberto: lei de acesso à informação nos executivos municipais da região sul. Florianópolis: Fundação Boiteux, 2012.

SÃO PAULO. Portal do Governo do Estado de São Paulo. Disponível em: <www.saopaulo.sp.gov. br/>. Acesso em: 4 dez. 2013.

TORRES, Elisabeth F. T.; MAZZONI, Alberto A.; ALVES, João B. da M. A acessibilidade à informação no espaço digital. Ciência da Informação, Brasília, v. 31, n. 3, p. 83-91, set./dez. 2002.

VEREZA, Claudio. Artigo 29 - Participação na vida política e pública. In: RESENDE, Ana P.C.; VITAL, Flavia M. de P. (Coord.). A Convenção sobre os Direitos das Pessoas com Deficiência comentada. Brasília: Secretaria Especial dos Direitos Humanos; Coordenadoria Nacional para Integração da Pessoa Portadora de Deficiência, 2008. p. 98-100.

Rosane Leal da Silva é doutora em direito pela Universidade Federal de Santa Catarina (UFSC). Professora adjunta do Programa de Pós-Graduação em Direito (PPGD) e do Curso de Direito da Universidade Federal de Santa Maria (UFSM). Líder do Grupo de Pesquisa Núcleo de Direito Informacional (UFSM). Realiza pesquisas sobre governo eletrônico financiadas pelo CNPq. E-mail: rolealdasilva@gmail.com.

Letícia Almeida de la Rue é mestranda do Programa de Pós-graduação em Direito da Universidade Federal de Santa Maria (UFSM), área de concentração: Direitos Emergentes da Sociedade Global, Linha de Pesquisa: Direitos na Sociedade em Rede. E-mail: leticiarue@gmail.com. 